\title{
The Mostela: an adjusted camera trapping device as a promising non-invasive tool to study and monitor small mustelids
}

\author{
Jeroen Mos ${ }^{1,2} \cdot$ Tim Ragnvald Hofmeester ${ }^{1,3}$
}

Received: 28 February 2020 / Accepted: 27 May 2020

(C) The Author(s) 2020, corrected publication 2021

\begin{abstract}
In spite of their potential important role in shaping small mammal population dynamics, weasel (Mustela nivalis) and stoat (Mustela erminea) are understudied due to the difficulty of detecting these species. Furthermore, their conservation status in many countries is unknown due to lack of monitoring techniques. There is thus an important need for a method to detect these small mustelids. In this study, we tested the efficiency of a recently developed camera trapping device, the Mostela, as a new technique to detect mustelids in a study area near Dieren, the Netherlands. We placed Mostelas in linear landscape features, and other microhabitats thought to be frequently visited by weasels, from March to October 2017 and February to October 2018. We tested for yearly and monthly differences in site use and detectability, as well as the effect of entrance tube size, using an occupancy modelling framework. We found large seasonal differences in site use and detectability of weasels with the highest site use in June to October and highest detection probability in August and September. Detection probability was approximately two times higher for Mostelas with a $10-\mathrm{cm}$ entrance tube compared with $8-\mathrm{cm}$. Furthermore, we were able to estimate activity patterns based on the time of detection, identify the sex in most detections $(69.5 \%)$, and distinguish several individuals. Concluding, the Mostela seems promising as a non-invasive monitoring tool to study the occurrence and ecology of small mustelids. Further development of individual recognition from images would enable using the Mostela for density estimates applying capture-recapture models.
\end{abstract}

Keywords Mustelidae $\cdot$ Wildlife monitoring $\cdot$ Bayesian occupancy model $\cdot$ Hierarchical analysis $\cdot$ Trail camera $\cdot$ Camera trap

\section{Introduction}

Small mustelids like weasel (Mustela nivalis) and stoat (M. erminea) play a complex role within natural systems as the most common specialist predators involved in rodent

Communicated by: Karol Zub

Electronic supplementary material The online version of this article (https://doi.org/10.1007/s13364-020-00513-y) contains supplementary material, which is available to authorized users.

Tim Ragnvald Hofmeester

tim.hofmeester@slu.se

1 Dutch Small Mustelid Foundation, Goudreinette 10, 6922 AE Duiven, The Netherlands

2 Mos Ecologisch Advies en Onderzoek, Goudreinette 10, 6922 AE Duiven, The Netherlands

3 Department of Wildlife, Fish, and Environmental Studies, Swedish University of Agricultural Sciences, Skogsmarksgränd 7, SE-90736 Umeå, Sweden population cycles (Tapper 1979; Jedrzejewski and Jędrzejewska 1993; Norrdahl and Korpimäki 1995; King and Powell 2010; Korpela et al. 2014). In spite of their widespread distribution, it is argued that populations of small mustelids are in decline over large parts of Europe (e.g., Hellstedt et al. 2006; Gisbert and Santos-Reis 2007; Torre et al. 2018). Data supporting this potential decline are, however, lacking over large parts of their range due to the difficulty in monitoring these species. Thus, there is a great need for a method to study and monitor small mustelids.

Weasels and stoats are rarely seen and do not leave easily visible field signs (King and Edgar 1977; King and Powell 2010). Hunting statistics have been used to monitor small mustelids in the past but the decrease in interest in fur rendered this method useless in most areas (but, see McDonald and Harris 1999; Sainsbury et al. 2019). Similarly, live trapping has been used successfully in the past (e.g., King 1980; Zub et al. 2008), but non-invasive methods are preferred, especially for long-term and large-scale monitoring, and with respect to animal welfare. 
Snow tracking and tracking tunnels have been extensively used to monitor small mustelids (e.g., Graham 2002; Korpela et al. 2014), but these methods suffer from the fact that it is often difficult to distinguish tracks from male weasels and female stoats, which overlap in footprint size (King and Powell 2010). Furthermore, weasels and stoats make use of the subnivean space underneath the snow, making it difficult to interpret snow tracking results. As for many other species, hair trapping with subsequent DNA analysis has been used for small mustelids, but with varying success (García and Mateos 2009; Gleeson et al. 2010). Furthermore, DNA analysis can be costly. In contrast to live trapping or genetics-based methods, the use of cameras to monitor terrestrial small mammals can be more cost-effective (Bondi et al. 2010).

Camera traps or trail cameras are increasingly used to study and monitor wildlife (Burton et al. 2015). However, camera traps often fail to detect small and relatively fast-moving species, due to the sensitivity of the passive-infrared sensor that triggers these devices (Meek et al. 2014; Kolowski and Forrester 2017). Several devices have been developed to monitor small mammals using adjusted camera traps, by reducing the distance over which animals can be detected (MCCleery et al. 2014; Soininen et al. 2015). However, the detection of small mustelids on these devices has, so far, been relatively low and these methods require the adjustment of the camera traps themselves. As tracking tunnels are effective in attracting small mustelids, we decided to combine a tracking tunnel and a regular camera trap to make use of the positive properties of both methods.

Similarly to elsewhere in Europe, the populations of weasel and stoat in the Netherlands are expected to be declining, but data supporting this expectation are lacking. In 2017-2019, both species have been given an increased protective status in five provinces in the Netherlands, increasing the need for a reliable, easy to use, and cost-effective monitoring method (Vos et al. 2016; Bouwens 2017; Scholten-Huizendveld 2019). In this paper, we present the "Mostela" concept, a recently developed non-invasive tool to study and monitor weasel and stoat. We describe the construction of the Mostela which was used to monitor a field site in the Netherlands during two consecutive years. We used Bayesian occupancy modelling to estimate the daily detection probability of Mostelas in different months and between constructions with two sizes of entrance tubes. We expected that Mostelas would have the highest detectability in autumn, when weasel population density is expected to be highest (King and Powell 2010), as a larger number of individuals would both increase the likelihood of a site being used (occupancy probability) as the number of individuals that are likely to visit a single Mostela, which increases the detection probability. Furthermore, we show the potential applicability of data gathered using the Mostela to study daily activity patterns, sex ratios, and the recognition of individuals.

\section{Methods}

\section{Description of the Mostela}

The "Mostela" (Fig. 1) was designed to capture footage of small mustelids. It combines a regular camera trap with a footprint tracking tunnel ( $\varnothing 8 \mathrm{~cm}$ or $10 \mathrm{~cm}, \mathrm{PVC}$ drainpipe) in a wooden box (12-mm shuttering plywood). By combining a tracking tunnel with a camera trap, we aimed to utilize the seemingly high detection probability of tracking tunnels with the increased identification possibilities of a camera trap while obtaining detection rates comparable with studies using only tracking tunnels. In order to get a sharp image of the animals inside the camera box, we placed an additional +2 -dioptre lens (obtained from a set of plastic reading glasses) in front of the camera.

\section{Field test}

To evaluate the Mostela concept, we deployed cameras to detect small mustelids in the estate "Hof te Dieren" near the village of Dieren in the central-eastern part of the Netherlands $\left(52^{\circ} 02^{\prime} \mathrm{N}, 6^{\circ} 06^{\prime} \mathrm{E}\right.$; Fig. 2$)$. The study area comprises 40 ha of heterogeneous habitat consisting of a mosaic of pastures divided by hedges and several small tree stands (Fig. 2). Management of the pastures consists mainly of extensive grazing by young cattle and partly of machine mowing and manure injection. Hedges are trimmed annually in late summer. Because the study area is situated in the floodplain of the river IJssel, about $500 \mathrm{~m}$ from the river, the area can be wet during winter and early spring. We conducted field work in the periods March-October 2017 and February-October 2018. In 2017, we used one type of camera (Bushnell Trophy Cam HD; Bushnell Outdoor Products, Overland Park, KS, USA) set to record 30-s videos when triggered, after which there was a 1-min delay before they could be triggered again. In 2018, we expanded the study with another seven camera types (Table S1), all set to record 30-s videos when triggered with a 1-min delay. We placed the Mostelas near trails, hedgerows, and natural corridors thought to be frequently used by small mustelids. We refer to each placement of a Mostela as a deployment. In 2017, every other week (video) footage was recovered from the cameras, tracking plates were checked for footprints of small mustelids, Mostelas were moved to another location within the study area, and batteries were replaced where necessary, resulting in 2-week deployments. On average, three Mostelas were deployed simultaneously with an average inter-Mostela distance of $143 \mathrm{~m}$. In 2018, the checking and moving interval was increased to 4 weeks, resulting in 4-week deployments. We also increased the number of Mostelas in 2018, resulting in an average of eight Mostelas in the field simultaneously with an average inter-Mostela distance of $129 \mathrm{~m}$. Mostelas were moved 


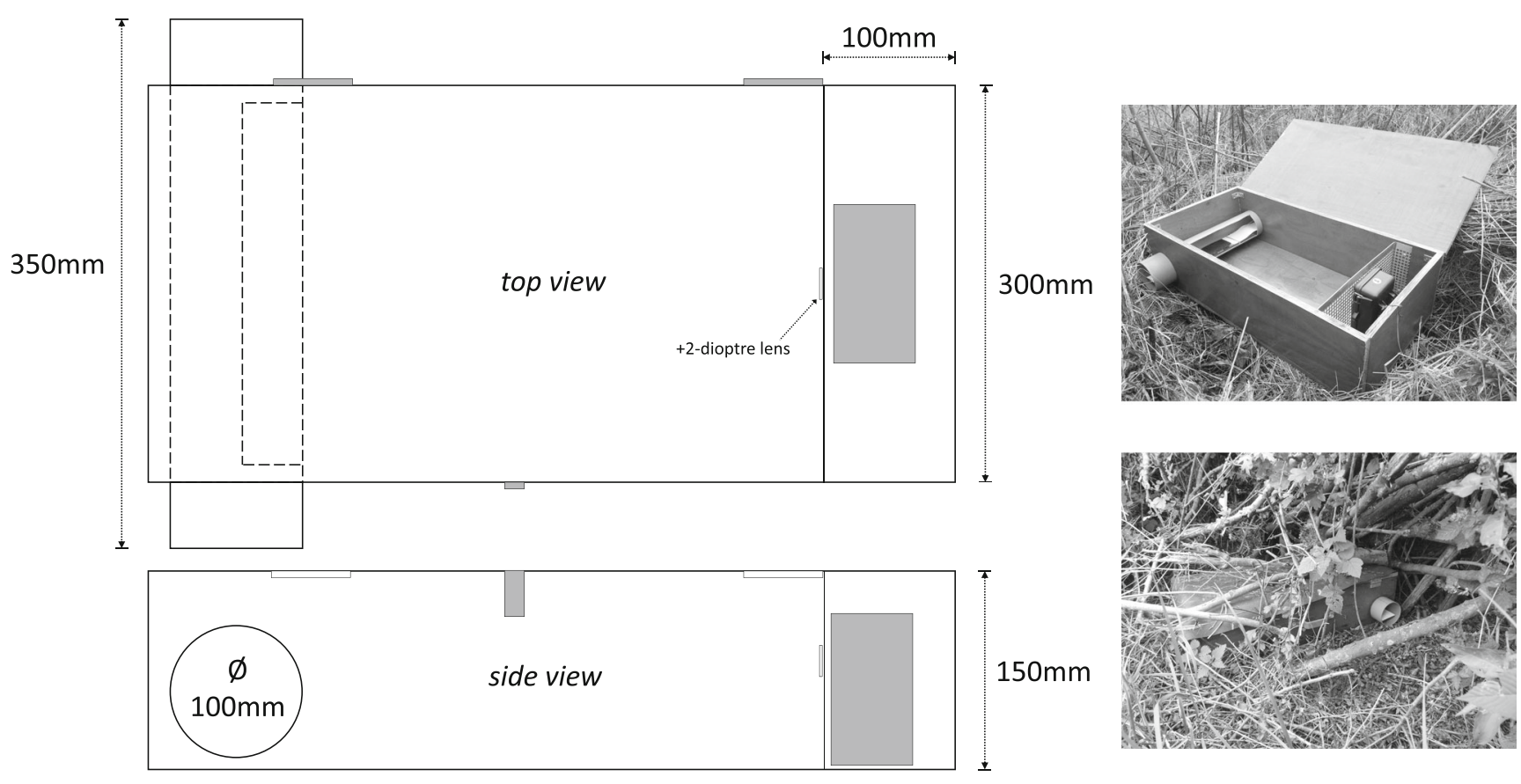

$610 \mathrm{~mm}$

Fig. 1 Design specifications of the Mostela and an example in the field. The grey square shows the location of the camera trap
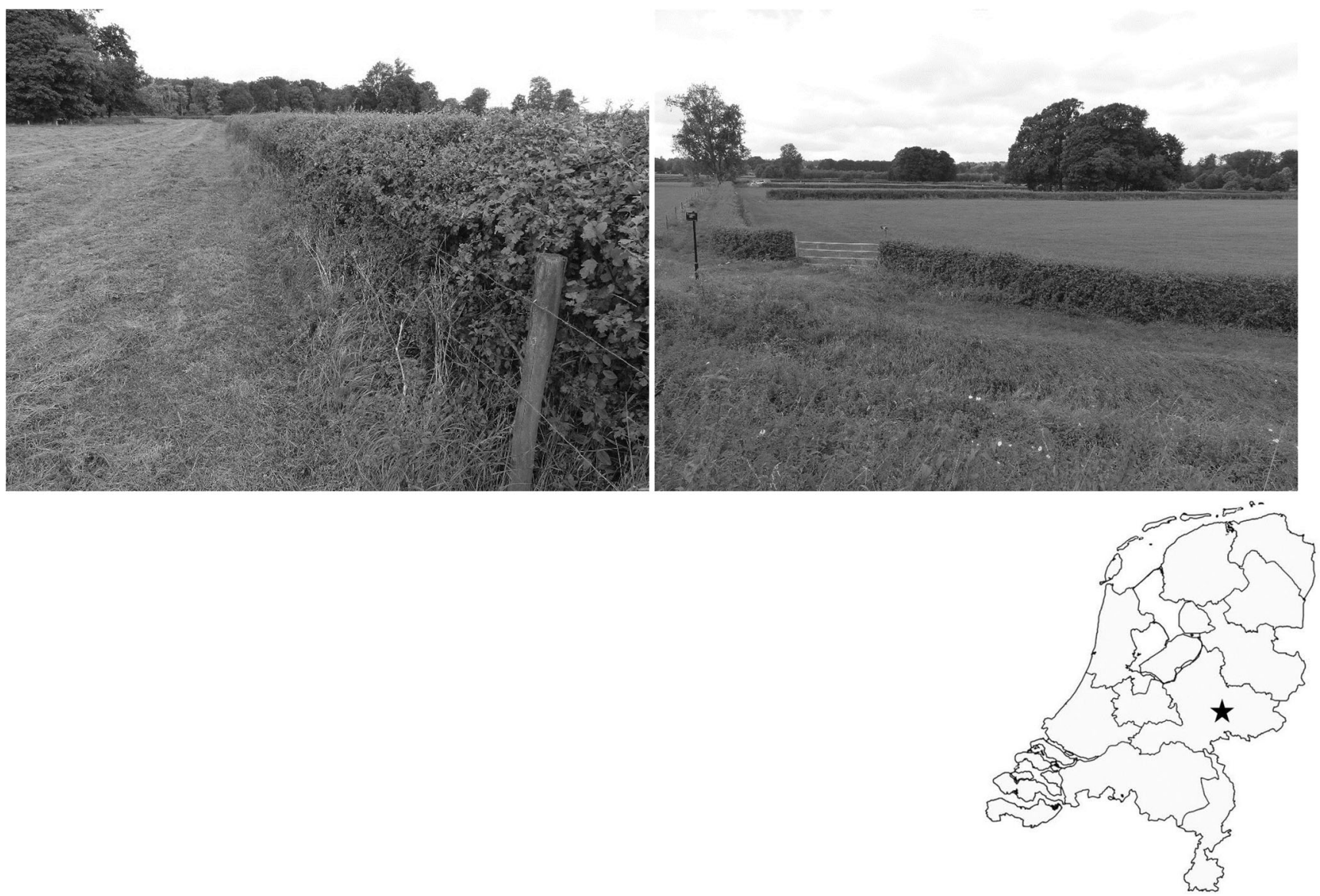

Fig. 2 Impression of the study area "Hof te Dieren" with a map showing the location of the study site within the Netherlands 
throughout the study area to enable us to cover the whole area with a limited number of Mostelas, a practice that is common in camera trapping studies (Burton et al. 2015). In both years, we did not use any form of bait or lure in the Mostelas and tested the functionality of tracking tunnels of two different sizes $(\varnothing 8$ and $10 \mathrm{~cm})$.

\section{Bayesian occupancy model}

In order to test the efficiency of the Mostela to detect small mustelids, we applied a single-season Bayesian occupancy model on each of the 2 years of data (Kéry and Royle 2016). As we monitored a mobile species with detection stations relatively close to each other, we interpret occupancy as site use of the direct surrounding of a Mostela during deployment rather than overall occupancy of the study area (Steenweg et al. 2018). We constructed daily detection histories based on the date of deployment and retrieval of each Mostela. The only small mustelid we detected was common weasel (Mustela nivalis) so we only report results for this species.

We performed separate analyses on data from each year. Although we used multiple camera trap models in 2018, we had insufficient deployments of the different camera types in locations where weasels were detected to estimate the effect of camera model on detection probabilities. However, as camera models were equally distributed over the study area and in equal numbers, we do not expect differences between camera models to influence our estimates.

We modelled the latent presence/absence of weasels $(z)$ at deployment $i$ as

$z_{i} \sim \operatorname{Bernoulli}\left(\psi_{i}\right)$

and the observation process for detection/non-detection $(y)$ at deployment $i$ during day $k$ as

$y_{i k} \mid z_{i} \sim \operatorname{Bernoulli}\left(z_{i} \cdot p_{i k}\right)$.

We included tube size as a covariate on the detection probability resulting in the following logistic regression models:

$$
\begin{aligned}
& \operatorname{Logit}\left(\psi_{i}\right)=\operatorname{logit}\left(\alpha_{0}\right)+\alpha_{\text {month }}+\gamma_{j} \\
& \operatorname{Logit}\left(p_{i k}\right)=\operatorname{logit}\left(\beta_{0}\right)+\beta_{\text {month }}+\beta_{1} \cdot \text { tubesize }_{i}
\end{aligned}
$$

We added a random intercept per month to both the state $\left(\alpha_{\text {month }}\right)$ and observation model $\left(\beta_{\text {month }}\right)$ to accommodate differences in both site use and detection probability between months. We added a random intercept $\left(\gamma_{j}\right)$ per site $j$ to the model as we surveyed the same locations multiple times. As we had a few missing values for tube type in 2017, we specified a prior for all covariate values (both missing and observed values) and estimated hyperparameters of that prior as described by Kéry and Royle (2016).
We ran the models for both years in JAGS (version 4.3.0, Plummer 2003) from R (version 3.6.0, R Core Team 2019) using the jagsUI package (Kellner 2019). We used vague priors for all parameters: a uniform distribution between 0 and 1 for all intercepts and a normal distribution with mean 0 and precision 0.001 for all slopes. We modelled the priors for the random intercepts per month and site using a normal distribution with a mean of 0 and precision of $1 / \sigma^{2}$ where $\sigma$ had a uniform distribution between 0 and 100 . We used initial values of 0 or 1 for $z_{i}$ (depending on the detection or nondetection of weasels at a deployment) and 0.5 for $\psi_{i}$ for both years. For all models, we ran 120,000 iterations $(+30,000$ iterations burn-in), thinned by 30 on three chains. Model convergence was checked using Gelman-Rubin diagnostics and visual inspection of the trace, density, and autocorrelation plots. To estimate the efficiency of the Mostela as a monitoring tool, we calculated the probability of a 2 -week deployment detecting a weasel given it is present in the habitat patch where the Mostela is located; we generated probability distributions of $1-(1-p)^{14}$ for each month for both years based on 120,000 iterations after the burn-in period. The model descriptions in JAGS language for the models for both years are given in Supplementary file S2.

\section{Daily activity pattern analysis}

To explore the potential of using Mostelas to determine daily activity patterns, we considered all mustelid recordings within 1-h intervals as a single visit and fitted circular probability density functions as implemented in the activity package (Rowcliffe 2019). We grouped multiple videos into single visits to reduce the effect of differences in exploration behavior between weasels on activity estimates. We split up the data into four seasons: winter (before 20 March), spring (20 March-20 June), summer (21 June-22 September), and autumn (after 22 September), to enable testing for differences between seasons. However, as our study was restricted to the summer half of the year, we only sampled spring and summer completely in both years. To ensure robust estimates, we only used seasonal subsets with more than 40 records and used a bandwidth adjustment multiplier of 1.5 as suggested by Rowcliffe et al. (2014). We used the adjusted sun time, calculated using the overlap package (Ridout and Linkie 2009), to adjust the time at which animals were recorded by standardizing sunrise at 6 am and sunset at $6 \mathrm{pm}$. We did this to correct for differences in timing of sunset and sunrise between seasons, enabling the estimation of differences in activity patterns between seasons. We then estimated the overlap between seasons, within years, using 1000 bootstrap iterations and a bandwidth adjustment multiplier of 1.5 in the activity package (Rowcliffe 2019). 


\section{Sex classification}

We determined sex by visually comparing body size in terms of head-body length (HBL), body height (excluding legs), and the visibility of testes. The larger animals $(\geq 20 \mathrm{~cm} \mathrm{HBL} / 3.5-$ $4 \mathrm{~cm}$ height) and animals with visible testes were classified as males. Females were sexed based on a smaller and more slender body size and when registered before July, assuming that from then on the first juveniles would be active and could be captured (Moors 1974). From July onwards, all animals which could not be sexed as a certain male were classified as "juvenile" which in this case includes adult females and juveniles of both sexes. Adult animals which could not be sexed and animals from which sex or life stage could not be determined were classified respectively as "adult unknown" and "not identifiable."

\section{Results}

We obtained a total of 5791 recordings during 2255 trap nights (568 trap nights in 2017 and 1687 in 2018). These contained predominantly small rodents and 259 detections of common weasel (Mustela nivalis; 113 in 2017 and 146 in 2018), resulting in trapping rates of 19.9 and 8.8 weasels per
100 trap nights for 2017 and 2018, respectively. Weasels were recorded throughout the study area (Fig. 3). Stoat (M. erminea) was not detected at all during this study. Besides weasels, we identified six other small mammal species: common or field vole (Microtus agrestis or arvalis), wood mouse (Apodemus sylvaticus), bank vole (Myodes glareolus), harvest mouse (Micromys minutus), common shrew (Sorex araneus), and pygmy shrew (Sorex minutus). In addition to mammals, a grass snake (Natrix natrix) was detected on six occasions. We occasionally detected weasel tracks on the track plates within the Mostelas, but never found a track in deployments without weasel videos.

\section{Seasonal site use}

We detected weasels during 58 of the 95 Mostela deployments, with naïve occupancy differing per month (Table 1). Because the Mostelas were spaced closer to each other than the average day range of weasels, we interpret occupancy as site use (Steenweg et al. 2018) and limit our interpretation of this site use probability. Modelled site use in 2017 ranged between 0.18 (95\% credibility interval (CI) $0.00-1.00$ ) in March and April and 1.00 (1.00-1.00) in July (Table 1). Site use in 2018 was less certain and ranged from $0.12(0.00-1.00)$ in March to 1.00 (1.00-1.00) in June (Table 1).
Fig. 3 Locations of Mostela deployments in the study area for the seasons with most effort (spring and summer) for both years. The symbols represent deployments with (circle) and without (triangle) weasel detections
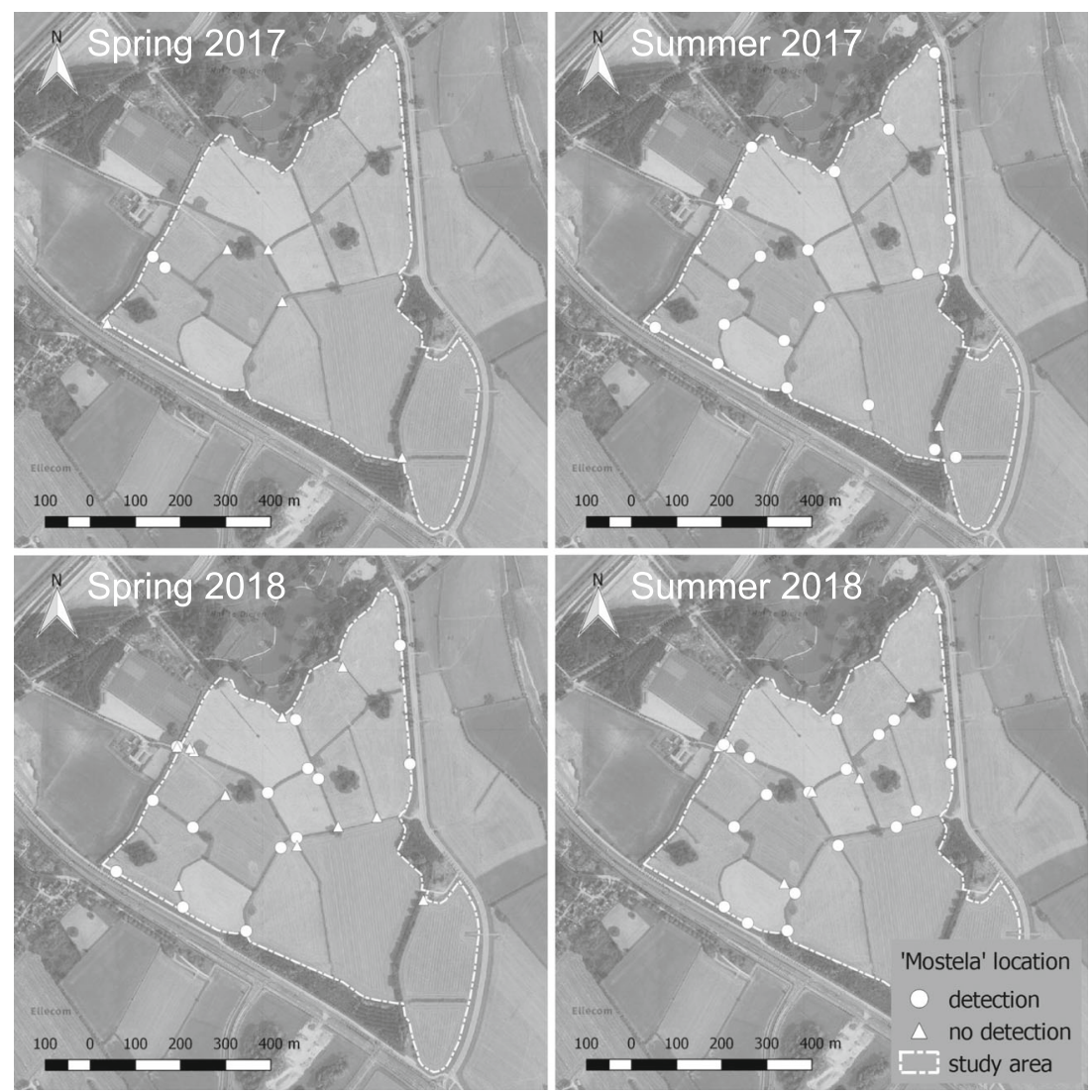
Table 1 Naïve occupancy given as the number of deployments that detected a weasel divided by the total number of deployments per month per year. The number of deployments is given between parentheses with the naïve estimate. The mean modelled estimate is given including $95 \%$ credibility interval between brackets

\begin{tabular}{|c|c|c|c|c|}
\hline \multirow[t]{2}{*}{ Month } & \multicolumn{2}{|l|}{2017} & \multicolumn{2}{|l|}{2018} \\
\hline & Naïve estimate & Model estimate & Naïve estimate & Model estimate \\
\hline February & - & - & $0(1)$ & $0.34(0.00-1.00)$ \\
\hline March & $0(2)$ & $0.18(0.00-1.00)$ & $0(5)$ & $0.12(0.00-1.00)$ \\
\hline April & $0(2)$ & $0.18(0.00-1.00)$ & $0.60(5)$ & $0.97(0.17-1.00)$ \\
\hline May & $0(1)$ & $0.25(0.00-1.00)$ & $0.67(12)$ & $0.86(0.00-1.00)$ \\
\hline June & $0.50(4)$ & $0.73(0.00-1.00)$ & $0.33(9)$ & $1.00(1.00-1.00)$ \\
\hline July & $1.00(7)$ & $1.00(1.00-1.00)$ & $0.56(9)$ & $0.76(0.00-1.00)$ \\
\hline August & $0.82(11)$ & $0.99(0.98-1.00)$ & $0.75(8)$ & $0.76(0.00-1.00)$ \\
\hline September & $0.67(6)$ & $0.81(0.00-1.00)$ & $0.73(11)$ & $0.90(0.00-1.00)$ \\
\hline October & $1.00(2)$ & $0.91(0.00-1.00)$ & - & - \\
\hline
\end{tabular}

\section{Seasonal detection probability}

Daily detection probabilities in the Mostelas differed between seasons (Fig. 4). In 2017, daily detection probability was lowest in June $(0.07 ; 95 \%$ CI $0.02-0.17)$, and highest in September $(0.21 ; 0.11-0.34)$ based on a tube size of $8 \mathrm{~cm}$ (Fig. 4). In 2018, daily detection probability was lowest in June $(0.02 ; 0.01-0.05)$, and highest in August $(0.18 ; 0.12-$ $0.24)$ and September $(0.18 ; 0.13-0.24)$ based on a tube size of $8 \mathrm{~cm}$ (Fig. 4). Estimates for all months for both tube sizes are given in supplementary table S3.

\section{Effect of tube size}

In 2017, we found a 1.9 times higher (log odds $0.63 ; 95 \%$ CI 0.10-1.16) detection probability in Mostelas with a tube size of $10 \mathrm{~cm}$ compared with Mostelas with a tube size of $8 \mathrm{~cm}$. In 2018, we found a similar but slightly smaller difference of 1.6
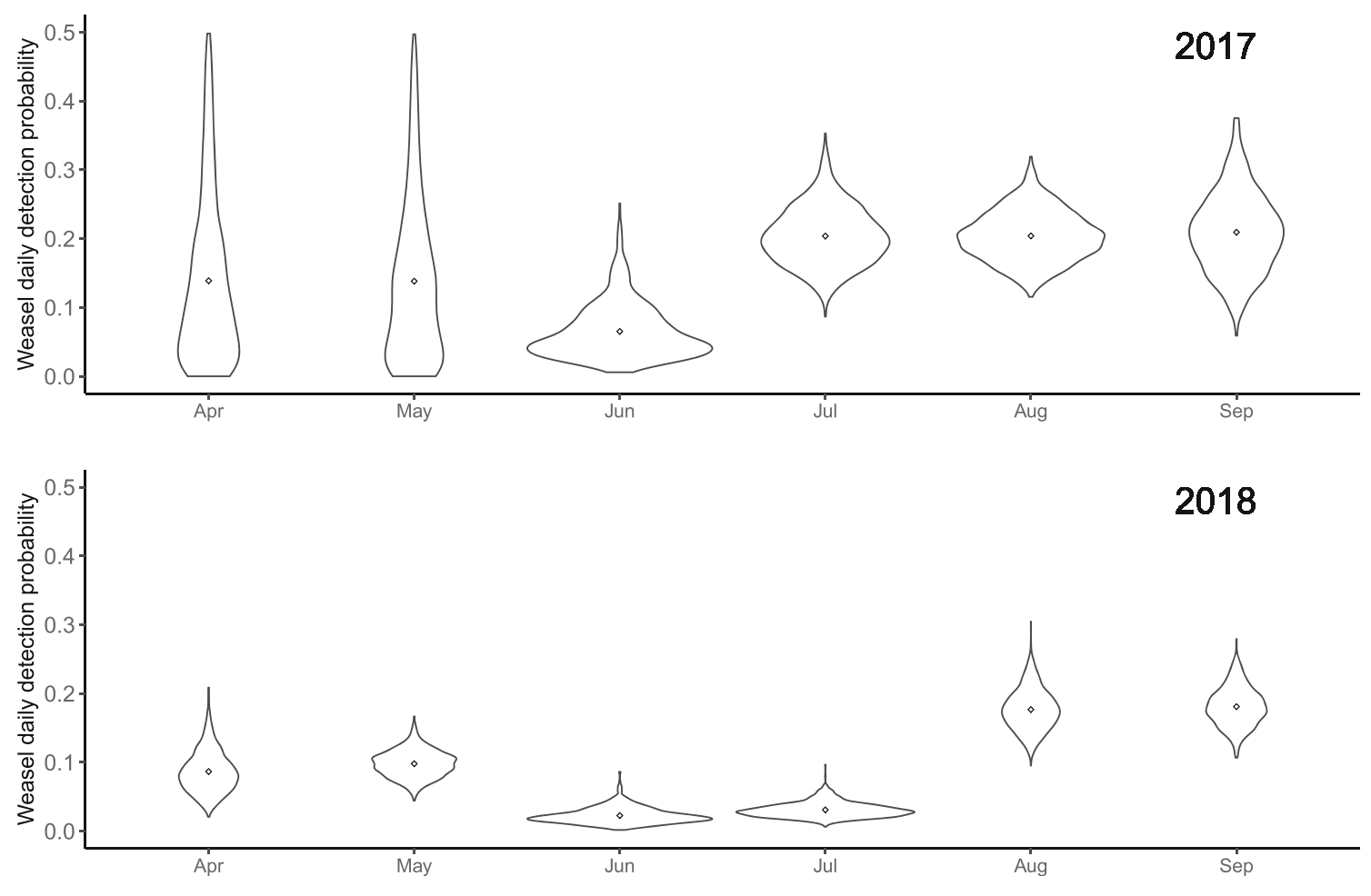

2018

Fig. 4 Violin plots of the posterior distribution of monthly detection probability (based on a random intercept and a tube size of $8 \mathrm{~cm}$ ) per year. The point denotes the mean of the distribution. The long tails for

April and May 2017 were cut off at 0.5 for better graphic representation. See Table S2 for all estimates 
times higher ( $\log$ odds $0.46 ; 95 \% \mathrm{CI}-0.03$ to 0.95$)$ detection with a tube size of $10 \mathrm{~cm}$ compared with $8 \mathrm{~cm}$.

\section{Two-week deployment}

In 2017, comparing both tube sizes, the 2-week detection probability ranged from $0.56(95 \%$ CI $0.20-0.92)$ with an 8$\mathrm{cm}$ tube in June to 0.99 (95\% CI 0.96-1.00) with a 10-cm tube in July, August, and September. In 2018, we found a slightly bigger range from 0.27 (95\% CI 0.08-0.52) with an 8-cm tube in June to 0.98 (95\% CI 0.92-1.00) with a 10-cm tube in July and August. Estimates for all months for both tube sizes are given in supplementary table S4.

\section{Daily activity patterns}

We had sufficient records per season to estimate activity patterns for summer $2017(n=105)$, spring $2018(n=46)$, and summer $2018(n=82)$. During both summers, weasel activity showed a crepuscular pattern with a clear peak in the morning just after sunrise and another smaller peak just before sunset, with very limited activity before sunrise and after sunset (Fig. 5). Summer activity patterns were consistent between years, with $89 \%$ overlap $(p=0.72)$.

In spring 2018, weasel activity had a more diurnal pattern with a single peak. We did not record any weasels before sunrise or after sunset in this season. Activity patterns indeed differed between spring and summer 2018 , but only slightly as there was still $73 \%$ overlap $(p=0.01)$.

\section{Individual identification}

On several occasions we could identify individual animals from video recordings based on a combination of body size and distinct coat patterns (gular spots and the boundary between the brown and white fur; Fig. 6). From the 58 deployments where we recorded weasels, 45 had multiple records of weasels from which at least two individuals could be identified on 19 deployments, and three individuals on five deployments. Only a few individuals had such characteristic spot patterns that these could be individually identified regardless of location and time restrictions. Furthermore, we were able to identify the sex for 173 of the 259 detections $(69.5 \%)$, of which 163 were classified as males and 10 as females. The remaining animals were classified as "adult unknown" (4), as "juveniles" (76), or as "not identifiable" (6). When using all animals identified as male, female, or juvenile, we found an average male-biased (65\%) sex ratio of 1:0.53 males to females/juveniles.

\section{Discussion}

Here, we present a novel camera trapping device, the Mostela, developed to detect small mustelids, and tested it during two field seasons in a study site in the Netherlands to quantify its functioning as a monitoring tool. We detected weasels with a daily detection probability between 0.1 and 0.2 during most of the year. Furthermore, we were able to estimate daily activity patterns based on time of detection, determine the sex of the majority of "captured" individuals, and identify some

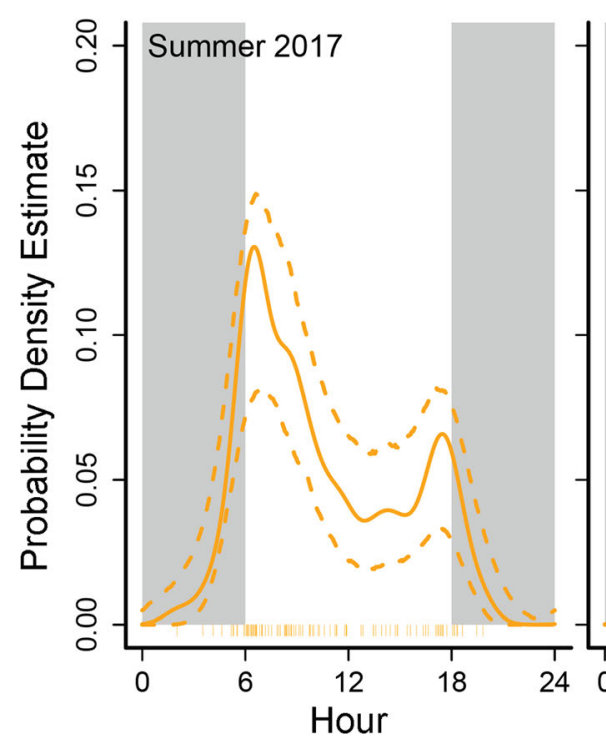

Fig. 5 Activity patterns of weasel for summer 2017 and spring and summer 2018 based on Mostela detections. Activity estimates are shown with $95 \%$ confidence interval (dotted line) and night time is
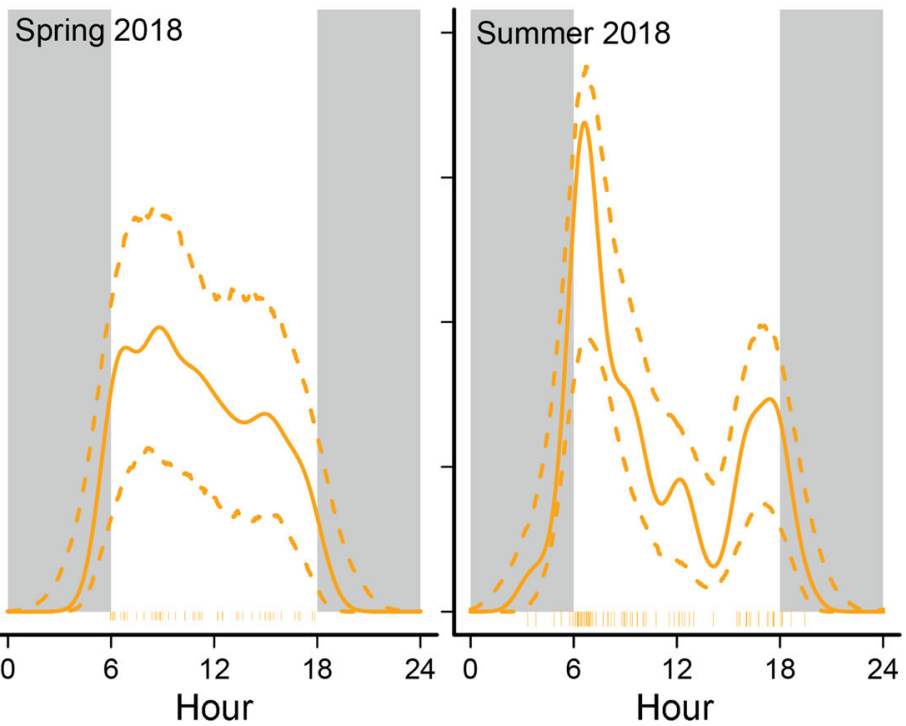

depicted by the gray shading (with standardized sunrise at 6 am and sunset at $6 \mathrm{pm}$ ). Orange ticks along the $x$-axis show the individual records used to estimate the activity pattern 

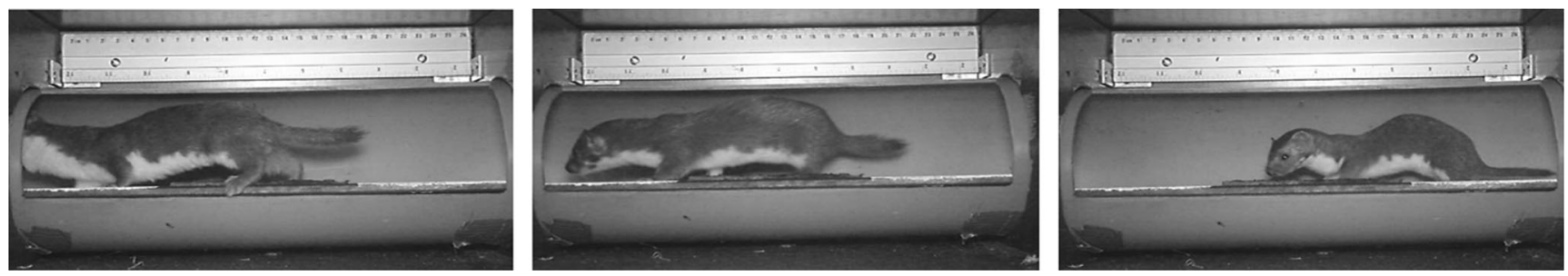

Fig. 6 Example of three individuals on stills from (white-flash) video footage from Mostelas. Individuals were identified based on body size and coat patterns. Note also the visible testes on the individual on the left-most image

individuals. The Mostela thus showed great promise as a monitoring tool that can both determine presence/absence of species and provide data on activity and sex ratio. Further development of individual identification could allow for (spatially explicit) capture-recapture or mark-resight models to estimate weasel population density. However, we did not detect any stoats in this study, likely due to the absence or very low population density of the species in our study site. Thus, further studies are needed to determine the effectiveness of the method to monitor this species.

Both site use probability and detection probability in this study were highest in summer and the beginning of autumn. This is to be expected, as weasel populations show the highest densities in these seasons due to the addition of juveniles born in spring and summer (King and Powell 2010). Furthermore, land management and farming practices have been described as being of importance for the spatial distribution and behavior of small mustelids, as they influence both habitat features, such as cover, and prey availability (Macdonald et al. 2004; Zub et al. 2008; King and Powell 2010; Mougeot et al. 2020). As most Mostelas in our study were placed in hedgerows that only provide cover during the growing season (Figs. 2 and 3), we speculate that, apart from changes in population density, mowing practices might have influenced the seasonal pattern in site use and detection probabilities we observed. In spring, the vegetation on the pastures surrounding the hedgerows increased in height, supplying both food and cover for voles and cover for weasels. This could lead to increased use of this part of the landscape and reduced use of the hedgerows. After mowing in late spring, the cover disappears and weasels are bound to the hedgerows, leading to higher site use and detection probabilities. Unfortunately, we lacked both sufficient information on mowing dates and deployments in the open part of the landscape to test this hypothesis.

We found a daily detection probability between 0.1 and 0.2 during most months, which is relatively high compared with most camera trapping studies, where detection histories are often combined for multiple days due to low detectability (Burton et al. 2015). Only Evans et al. (2019) found a similar daily detection probability of 0.24 for stoat, but they used both bait and lure. A previous publication using the Mostela had a much lower number of detections, showing that there likely are differences between study areas (Croose and Carter 2019).
Croose and Carter (2019) had trapping rates of 1.4 weasels per 100 trap nights and 0.1 stoat per 100 trap nights, which are much lower than the number we obtained for weasels (19.9 and 8.6 in 2017 and 2018, respectively). Similarly, Soininen et al. (2015) obtained a trapping rate of 0.2 stoats per 100 trap nights in the camera trapping device they developed to study small mammals under the snow. Our estimates were more similar to, but still higher than, those obtained by tracking tunnels: 0-6 weasels per 100 trap nights (Graham 2002). Thus, we had high success in detecting weasels, especially considering we did not use bait or lure, which might be caused by a combination of a well-performing method and a study site where weasel activity was concentrated, making it easier to target locations with relatively high use of weasels.

We found that a Mostela equipped with a tracking tube of $10 \mathrm{~cm}$ had a 1.6-1.9 times higher detection probability compared with a Mostela equipped with an 8-cm tube. This was in contrast to our expectation, as a larger entrance tube could potentially increase the likelihood of larger carnivores, such as stoats, to enter the box, which could result in weasels avoiding a Mostela. Thus, our result might be dependent on the apparent absence of stoats in our study area. As tubes with a diameter of $10 \mathrm{~cm}$ have been used to monitor weasels previously (Graham 2002), we would recommend the use of tubes with a diameter of $10 \mathrm{~cm}$ for studies of both weasel and stoat.

In this study, weasels were found to be predominantly active by day, consistent with previous studies (Jedrzejewski et al. 2000; Sundell et al. 2000; Brandt and Lambin 2005; Zub et al. 2013). Jedrzejewski et al. (2000) found similar differences over seasons, with slightly more uniform activity patterns in spring compared with summer, while Brandt and Lambin (2005) found a similar more crepuscular pattern with two peaks around sunrise and sunset in summer. Both these studies were based on radio-tracked weasels while we are, to our knowledge, the first to detect similar activity patterns using non-invasive methods. The difference in activity pattern between spring and summer might be a response to high midday temperatures in summer as weasels adjust their activity to avoid heat stress (Zub et al. 2013).

We were able to identify several individuals based on body size and coat patterns from the video footage recorded with the Mostela. For weasels of the subspecies vulgaris, it was shown previously that individuals can be identified from these 
characteristics (King 1979; Linn and Day 2009). However, in this study, we could not identify individuals in all videos, mainly due to some issues with lack of contrast in the infrared footage from the Bushnell cameras. The contrast of the images was much better, and the recognition of individuals therefore easier, using the Browning cameras. Thus, it is important to test the contrast of images produced by different camera trap models before using them in a Mostela if individual recognition of individuals is considered important. It is important to state that not all individuals need to be identifiable as the identification of a few individuals with unique spot patterns is sufficient to allow for density estimation using spatially explicit mark-resight models (Royle et al. 2014).

We found a male-biased sex ratio of $65 \%$ males in our dataset. The ratio in this study is similar to that in previous findings based on live trapping summarized by Moors (1974), $76.5 \%$ and $59 \%$ males, and King (1975), 75\% males. These male-biased captures are likely caused by (seasonal) differences in home ranges and hunting behavior between the sexes (King and Powell 2010), rather than true sex ratio. However, they could also be caused by sexual differences in seasonal mortality which can result in a male-biased sex ratio during summer (Zub et al. 2011). The identification of individuals and calculation of individual trap rates would enable the correction of differences in capture probability between the sexes which would allow the true sex ratio to be determined.

We captured footage of more than one individual weasel inside the Mostela at the same time on several occasions. A study on stoat and long-tailed weasel (M. frenata) showed that at the end of summer the young leave the den, but apparently travel together in family groups which resulted in captures of several individuals (Rust 1968). Therefore, the recording of multiple individuals at once might have been the result of mothers with young or groups of siblings moving together.

We were able to identify six small mammal species besides weasel. Among these were the pygmy shrew and harvest mouse, which shows that the Mostela can detect even the smallest species of mammal. Thus, the Mostela might also be applicable for non-invasive monitoring of small mammals, other than mustelids, which needs further exploration. We detected all species without the use of a bait or lure. Weasels can be caught without bait if the trap is well placed, because mustelids are naturally curious and investigate any hole or burrow when hunting. Previous studies have shown that bait or lure can increase the effectiveness of trapping of weasels (King and Edgar 1977). The lack of stoats in our study might be a result of the lack of lure as Croose and Carter (2019) detected this species using lure in their Mostelas. However, the use of bait has several drawbacks, such as the potential attraction of larger predators which might reduce weasel presence (King and Powell 2010; Lambin 2018), potential for habituation, and violation of several assumptions often made when analyzing camera trap data (Hofmeester et al. 2019).
Nevertheless, rodents using the Mostela likely leave a natural scent lure, which is accentuated by the recording of grass snakes in Mostelas in this study and a study by Croose and Carter (2019) and a recording of a Western whip snake (Hierophis viridiflavus) in the Dordogne, France (J. Mos, personal observation).

Overall, we think that the Mostela is a promising noninvasive tool to study and monitor small mustelids, especially weasels. Furthermore, the relatively easy setup and low associated costs make it a great method to use in volunteer-run monitoring programs. Given the high daily detection probability in July-September, it is sufficient to deploy a Mostela with a $10-\mathrm{cm}$ entrance tube for 2 weeks during that period to determine presence of weasel at a site. However, in early spring and autumn, and potentially in winter when we did not deploy Mostelas, longer deployments might be needed to ensure good presence/absence estimates. Similarly, the study by Croose and Carter (2019) suggests that detection probabilities for stoats are lower than those for weasel, calling for longer trapping periods when monitoring stoats. In general, it would be beneficial to test the Mostela in a larger number of study sites, to test the generality of our results, as well as the functionality of the Mostela to monitor stoats. The additional information that can be gathered with Mostelas, such as the time of detection and the recognition of individuals, will further increase the utility of the data for studies of activity patterns and density estimates. One promising future application might be for estimating density of common weasels based on (spatially explicit) capture-recapture or mark-resight models.

Acknowledgments We are grateful to Wilke Schoenmaker and Thijs Grosheide of Stichting Twickel for arranging access to the study site at "Hof te Dieren" and to Lennart Suselbeek for the borrowing and testing of different camera trap brands and models. Thanks to Erwin van Maanen and Fokko Bilijam for the mental support and Lizzie Croose and Steve Carter from the Vincent Wildlife Trust for fruitful discussions leading to further development of the method. We thank Karol Zub for useful comments on a previous version that greatly improved this manuscript and three anonymous reviewers whose suggestions and comments greatly improved our manuscript.

Availability of data and material All data used in the analyses are supplied at https://github.com/Tim-Hofmeester/mostela-dieren. Raw camera trap footage can be supplied upon reasonable request.

Code availability The codes used in the analyses are supplied in the supplementary material and at https:/github.com/Tim-Hofmeester/ mostela-dieren.

Authors' contributions Both authors contributed to the study design and co-wrote the first draft of the manuscript. Material preparation and data collection were performed by Jeroen Mos. Analyses were performed by Tim Hofmeester. Both authors read and approved the final manuscript.

Funding information Open access funding provided by Swedish University of Agricultural Sciences. 


\section{Compliance with ethical standards}

Conflict of interest The authors declare that they have no conflicts of interest.

Ethics approval Not applicable

Consent to participate Not applicable

Consent for publication Not applicable

Open Access This article is licensed under a Creative Commons Attribution 4.0 International License, which permits use, sharing, adaptation, distribution and reproduction in any medium or format, as long as you give appropriate credit to the original author(s) and the source, provide a link to the Creative Commons licence, and indicate if changes were made. The images or other third party material in this article are included in the article's Creative Commons licence, unless indicated otherwise in a credit line to the material. If material is not included in the article's Creative Commons licence and your intended use is not permitted by statutory regulation or exceeds the permitted use, you will need to obtain permission directly from the copyright holder. To view a copy of this licence, visit http://creativecommons.org/licenses/by/4.0/.

\section{References}

Bondi ND, White JG, Stevens M, Cooke R (2010) A comparison of the effectiveness of camera trapping and live trapping for sampling terrestrial small-mammal communities. Wildl Res 37:456-465. https:// doi.org/10.1071/WR10046

Bouwens S (2017) Handreiking Kleine Marters in relatie tot soortbescherming

Brandt M, Lambin X (2005) Summertime activity patterns of common weasel Mustela nivalis vulgaris under differing prey abundances in grassland habitats. Acta Theriol 50:67-79. https://doi.org/10.1007/ BF03192620

Burton AC, Neilson E, Moreira D, Ladle A, Steenweg R, Fisher JT, Bayne E, Boutin S (2015) Wildlife camera trapping: a review and recommendations for linking surveys to ecological processes. J Appl Ecol 52:675-685. https://doi.org/10.1111/1365-2664.12432

Croose E, Carter SP (2019) A pilot study of a novel method to monitor weasels (Mustela nivalis) and stoats (M. erminea) in Britain. Mammal Communications 5:6-12

Evans B, Mosby C, Mortelliti A (2019) Assessing arrays of multiple trail cameras to detect North American mammals. PLoS One 14: e0217543. https://doi.org/10.1371/journal.pone.0217543

García P, Mateos I (2009) Evaluation of three indirect methods for surveying the distribution of the least weasel Mustela nivalis in a Mediterranean area. Small Carniv Conserv 40:22-26

Gisbert J, Santos-Reis M (2007) Mustela nivalis Linnaeus 1766. In: Palomo L.J., Gisbert J., Blanco J.C. (Eds.). Atlas y libro rojo de los mamíferos terrestres de España. Dirección General para la Biodiversidad SECEM y SECEMU, Madrid, pp 283-286

Gleeson DM, Byrom AE, Howitt RLJ (2010) Non-invasive methods for genotyping of stoats (Mustela erminea) in New Zealand: potential for field applications. N Z J Ecol 34:356-359

Graham IM (2002) Estimating weasel Mustela nivalis abundance from tunnel tracking indices at fluctuating field vole Microtus agrestis density. wbio 8:279-287. https://doi.org/10.2981/wlb.2002.025

Hellstedt P, Sundell J, Helle P, Henttonen H (2006) Large-scale spatial and temporal patterns in population dynamics of the stoat, Mustela erminea, and the least weasel, M. nivalis, in Finland. Oikos 115: 286-298. https://doi.org/10.1111/j.2006.0030-1299.14330.x

Hofmeester TR, Cromsigt JPGM, Odden J, Andrén H, Kindberg J, Linnell JDC (2019) Framing pictures: a conceptual framework to identify and correct for biases in detection probability of camera traps enabling multi-species comparison. Ecology and Evolution 9:2320-2336. https://doi.org/10.1002/ece3.4878

Jedrzejewski W, Jędrzejewska B (1993) Predation on rodents in Białowieza primeval forest, Poland. Ecography 16:47-64. https:// doi.org/10.1111/j.1600-0587.1993.tb00058.x

Jedrzejewski W, Jedrzejewska B, Zub K, Nowakowski W (2000) Activity patterns of radio-tracked weasels Mustela nivalis in Bialowieza National Park (E Poland). Annales Zoologici Fennici 37:

Kellner K (2019) jagsUI: a wrapper around "rjags" to streamline "JAGS" analyses. Version 1.5.1

Kéry M, Royle JA (2016) Applied hierarchical modeling in ecology: analysis of distribution, abundance and species richness in $\mathrm{R}$ and BUGS, 1st edn. Academic Press, London

King C (1980) Population biology of the weasel Mustela nivalis on British game estates. Ecography 3:160-168. https://doi.org/10. 1111/j.1600-0587.1980.tb00722.x

King C (1979) Moult and colour change in English weasels (Mustela nivalis). J Zool 189:127-134. https://doi.org/10.1111/j.1469-7998. 1979.tb03955.x

King CM (1975) The home range of the weasel (Mustela nivalis) in an English woodland. J Anim Ecol 44:639-668. https://doi.org/10. 2307/3616

King CM, Edgar RL (1977) Techniques for trapping and tracking stoats (Mustela erminea); a review, and a new system. New Zeal J Zool 4: 193-212. https://doi.org/10.1080/03014223.1977.9517953

King CM, Powell RA (2010) The natural history of weasels and stoats: ecology, behavior, and management, 2nd edn. Oxford University Press, Oxford

Kolowski J, Forrester T (2017) Camera trap placement and the potential for bias due to trails and other features. PLoS One 12:e0186679. https://doi.org/10.1371/journal.pone.0186679

Korpela K, Helle P, Henttonen H, Korpimäki E, Koskela E, Ovaskainen O, Pietiäinen H, Sundell J, Valkama J, Huitu O (2014) Predatorvole interactions in northern Europe: the role of small mustelids revised. Proc R Soc B Biol Sci 281:20142119. https://doi.org/10. 1098/rspb.2014.2119

Lambin X (2018) The population dynamics of bite-sized predators: prey dependence, territoriality, and mobility. In: Biology and conservation of musteloids. pp 129-148

Linn I, Day M (2009) Identification of individual weasels Mustela nivalis using the ventral pelage pattern. J Zool 148:583-585. https://doi. org/10.1111/j.1469-7998.1966.tb02975.x

Macdonald DW, Tew TL, Todd IAD (2004) The ecology of weasels (Mustela nivalis) on mixed farmland in southern England. Biologia 59:235-241

MCCleery RA, Zweig CL, Desa MA et al (2014) A novel method for camera-trapping small mammals. Wildl Soc Bull 38:887-891. https://doi.org/10.1002/wsb.447

Mcdonald RA, Harris S (1999) The use of trapping records to monitor populations of stoats Mustela erminea and weasels M. nivalis: the importance of trapping effort. J Appl Ecol 36:679-688. https://doi. org/10.1046/j.1365-2664.1999.00433.x

Meek PD, Ballard G, Claridge A, Kays R, Moseby K, O’Brien T, O'Connell A, Sanderson J, Swann DE, Tobler M, Townsend S (2014) Recommended guiding principles for reporting on camera trapping research. Biodivers Conserv 23:2321-2343. https://doi.org/ 10.1007/s10531-014-0712-8

Moors P (1974) The annual energy budget of a weasel, Mustela nivalis L., population in farmland 
Mougeot F, Lambin X, Arroyo B, Luque-Larena J (2020) Body size and habitat use of the common weasel Mustela nivalis vulgaris in Mediterranean farmlands colonised by common voles Microtus arvalis. Mammal Research 65:75-84. https://doi.org/10.1007/ s13364-019-00465-y

Norrdahl K, Korpimäki E (1995) Mortality factors in a cyclic vole population. Proceedings: Biological Sciences 261:49-53

Plummer M (2003) JAGS: a program for analysis of Bayesian graphical models using Gibbs sampling

R Core Team (2019) R: a language and environment for statistical computing. R Foundation for Statistical Computing, Vienna, Austria

Ridout MS, Linkie M (2009) Estimating overlap of daily activity patterns from camera trap data. J Agric Biol Environ Stat 14:322-337. https://doi.org/10.1198/jabes.2009.08038

Rowcliffe JM, Kays R, Kranstauber B, Carbone C, Jansen PA (2014) Quantifying levels of animal activity using camera trap data. Methods Ecol Evol 5:1170-1179. https://doi.org/10.1111/2041210X.12278

Rowcliffe M (2019) activity: animal activity statistics. Version 1.2. https://cran.r-project.org/package=activity

Royle JA, Chandler RB, Sollmann R, Gardner B (2014) Chapter 19 Spatial mark-resight models. In: Royle JA, Chandler RB, Sollmann R, Gardner B (eds) Spatial capture-recapture. Academic Press, Boston, pp 497-526

Rust C (1968) Procedure for live trapping weasels. J Mammal 49:318. https://doi.org/10.2307/1377994

Sainsbury KA, Shore RF, Schofield H, Croose E, Campbell RD, Mcdonald RA (2019) Recent history, current status, conservation and management of native mammalian carnivore species in Great Britain. Mammal Rev 49:171-188. https://doi.org/10.1111/mam. 12150

Scholten-Huizendveld HT (2019) Soortenbescherming in Overijssel Handreiking voor het aanvragen van een ontheffing

Soininen EM, Jensvoll I, Killengreen ST, Ims RA (2015) Under the snow: a new camera trap opens the white box of subnivean ecology. Remote Sens Ecol Conserv 1:29-38. https://doi.org/10.1002/rse2.2
Steenweg R, Hebblewhite M, Whittington J, Lukacs P, McKelvey K (2018) Sampling scales define occupancy and underlying occupancy-abundance relationships in animals. Ecology 99:172183. https://doi.org/10.1002/ecy.2054

Sundell J, Norrdahl K, Korpimäki E, Hanski I (2000) Functional response of the least weasel, Mustela nivalis nivalis. Oikos 90:501-508. https://doi.org/10.1034/j.1600-0706.2000.900308.x

Tapper S (1979) The effect of fluctuating vole numbers (Microtus agrestis) on a population of weasels (Mustela nivalis) on farmland. J Anim Ecol 48:603-617. https://doi.org/10.2307/4182

Torre I, Raspall A, Arrizabalaga A, Díaz M (2018) Weasel (Mustela nivalis) decline in NE Spain: prey or land use change? Mamm Res 63:501-505. https://doi.org/10.1007/s13364-018-0388-7

Vos CC, Broekmeyer MEA, Lammertsma DR, Jansman HAH (2016) Advies Noord-Brabantse vrijstellingslijst onder de nieuwe Wet natuurbescherming; Analyse in relatie tot artikel 75 Flora- en faunawet. Alterra Wageningen UR (University \& Research centre), Wageningen

Zub K, Fletcher QE, Szafrańska PA, Konarzewski M (2013) Male weasels decrease activity and energy expenditure in response to high ambient temperatures. PLoS One 8:e72646. https://doi.org/10. 1371/journal.pone.0072646

Zub K, Sönnichsen L, Szafrańska PA (2008) Habitat requirements of weasels Mustela nivalis constrain their impact on prey populations in complex ecosystems of the temperate zone. Oecologia 157:571582. https://doi.org/10.1007/s00442-008-1109-8

Zub K, Szafrańska PA, Konarzewski M, Speakman JR (2011) Effect of energetic constraints on distribution and winter survival of weasel males. J Anim Ecol 80:259-269. https://doi.org/10.1111/j.13652656.2010.01762.x

Publisher's note Springer Nature remains neutral with regard to jurisdictional claims in published maps and institutional affiliations. 